\title{
EDITORIAL
}

\section{Respiratory disease induced by drugs}

\author{
Ph. Camus
}

Adverse effects from drugs on the respiratory system have emerged as a significant topic in pulmonology, and represent a sizeable proportion of patients seen in pulmonary practice nowadays. Under the impetus of a French study group on drug-induced respiratory disease (DIRD), known as the Groupe d'Etudes de la Pathologie Pulmonaire Iatrogène (GEPPI), a comprehensive table of drugs initiating adverse respiratory reactions has been drawn up, and is presented in this issue of the Journal [1]. This table was designed to make it possible to determine rapidly: whether a given drug may induce respiratory problems; what pattern of involvement can be expected; an estimate of frequency of the adverse reaction, and significant references from a database of nearly 2,650 papers on DIRD. It was hoped that this table would become a companion document, at the bedside.

In addition to this hardcopy, a continuously upgraded list of drugs with typical chest radiograph(s), computed tomography (CT) scan(s) and pathology slide(s) is available on e-mail at http://www.epidaure.com/lungdrug, where cases may be notified confidentially. We may also be reached at: pneumo.dijon@planetb.fr whenever additional information is needed.

DIRD is a group of diseases that has changed markedly, mainly during the past $25 \mathrm{yrs}$. This is demonstrated by the growing literature on the topic, the output of

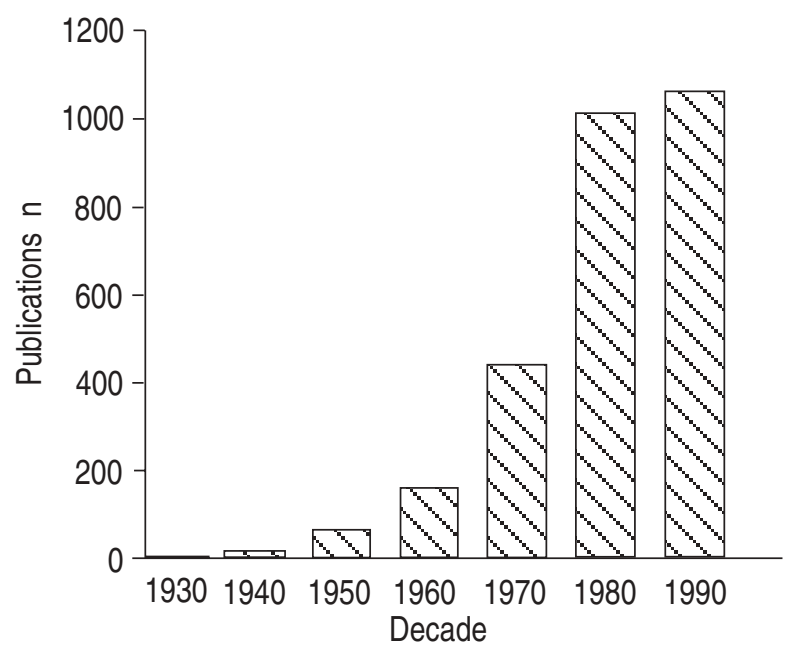

Fig. 1. - Number of publications on drug-induced respiratory disease (per decade) as a function of time. The current decade is an estimate.

Department of Pulmonary Disease and Intensive Care, University Medical Center at Dijon, France. which averages 100 clinical articles per year (fig. 1). Collectively, of approximately 2,650 clinical articles published so far, $32 \%$ are related to chemotherapeutic agents: bleomycin (226 papers); busulphan (58); cyclophosphamide (75); methotrexate (129); and nitrosoureas (46). Adverse pulmonary effects from: amiodarone (214 articles); ergolines (54); gold salts (133); minocycline (35); nitrofurantoin (135); nonsteroidal anti-inflammatory drugs (NSAIDs) (58); and sulphasalazine (22) point to all these drugs as being common offenders of the respiratory system, in addition to angiotensin-converting enzyme (ACE) inhibitors. On this basis, a brief historical perspective on DIRD is warranted.

The first notice of adverse effects of drugs on the respiratory system dates back to the years 1920-1930, when it was realized that aspirin could induce severe asthma attacks and even death [2].

In the 1940s, the then newer antibiotic drugs were associated with allergic pneumonia with or without eosinophilia or angiitis [3, 4], and gold was linked to the development of interstitial lung disease [5], although most of the literature on "gold lung" was published later [6-8].

The 1950s was an innovative decade, with the description of such varied and important drug-induced patterns as: lipoid pneumonia [9]; allergic pneumonia from para-aminosalicylic acid [10]; other anti-tuberculosis agents [11]; or nitrofurantoin [12]; the lupus erythematosus syndrome induced by hydralazine [13]; acute allergic pulmonary oedema from salicylates [14]; mediastinal lymphadenopathy or lymphoma from anticonvulsants [15]; and a severe diffuse pattern of organizing pneumonia, very reminiscent of what is now called diffuse bronchiolitis obliterans organizing pneumonia (BOOP), in patients exposed to hexamethonium [16].

The 1960-1969 decade was dominated by an overwhelming number of reports on nitrofurantoin lung. In addition, a worrisome picture of medication-induced pulmonary hypertension emerged, and an epidemic of this devastating illness in young females was ascribed to the appetite-suppressant, aminorex, which was withdrawn from the market [17]. For the first time, it became clear that one drug could induce more than one pattern of respiratory reactions. In the case of nitrofurantoin, these patterns included: acute allergic pneumonia, with or without eosinophilia in the blood [18]; subacute/chronic interstitial pneumonia, with or without a desquamative or eosinophilic pattern at histology [19-21]; bronchospasm [22]; anaphylaxis [23]; and pleural effusion [24]. In that decade also, alkylating agents [25], other antineoplastic drugs, including bleomycin [26] and methotrexate [27], imipramine [28], and sulphasalazine [29] emerged 
as novel causative drugs for DIRD. Newer drug-induced patterns of involvement were reported, and included ergoline-induced pleural fibrosis [30] and hydrochlorothiazide-induced pulmonary oedema [31].

The 1970s elapsed against a background of continuing interest in nitrofurantoin, gold or bleomycin pneumonia and drug-induced bronchospasm. However, novel offenders, such as nitrosoureas [32], cyclophosphamide [33], mitomycin [34], azathioprine [35], chlorambucil [36], melphalan [37], NSAID [38], and tetracycline/minocycline [39], progressively emerged. In addition, new and occasionally worrying patterns of DIRD were described, such as: penicillamine-induced bronchiolitis obliterans [40]; interstitial pneumonia [41]; and alveolar haemorrhage [42]. A study showed development of pulmonary oedema in parturients when high-dose i.v. $\beta_{2}$-agonists were used to retard term [43]. A transient picture of pulmonary oedema following blood transfusion was coined the "transfusion-related lung injury syndrome" [44]. A disturbing syndrome of generalized hypersensitivity with associated multiorgan failure and neurological symptoms was ascribed to salycilates [45] and, later, to phenytoin and carbamazepine [46]. Due to its propensity to induce pleural/pericardial fibrosis and because of additional extrapulmonary problems [47], practolol was taken off the market during these years.

Amiodarone became the most durable drug of the 1980 s, soon after the first report of amiodarone pneumonitis in 1980 [48]. This was followed by a surge of publications, which has since substantially decreased (fig. 2). It appeared that amiodarone could induce several distinctive clinicopathological patterns of involvement, including lung fibrosis [49], BOOP [50], and acute respiratory distress syndrome (ARDS), probably because of the potentiating effect of exposure to oxygen in some patients [51]. At the same time, treatments with nilutamide [52], and intravesical Bacille Calmette-Guérin [53] were associated with the development of interstitial lung disease. Low-dose methotrexate, as employed in the long-term treatment of rheumatoid arthritis, was

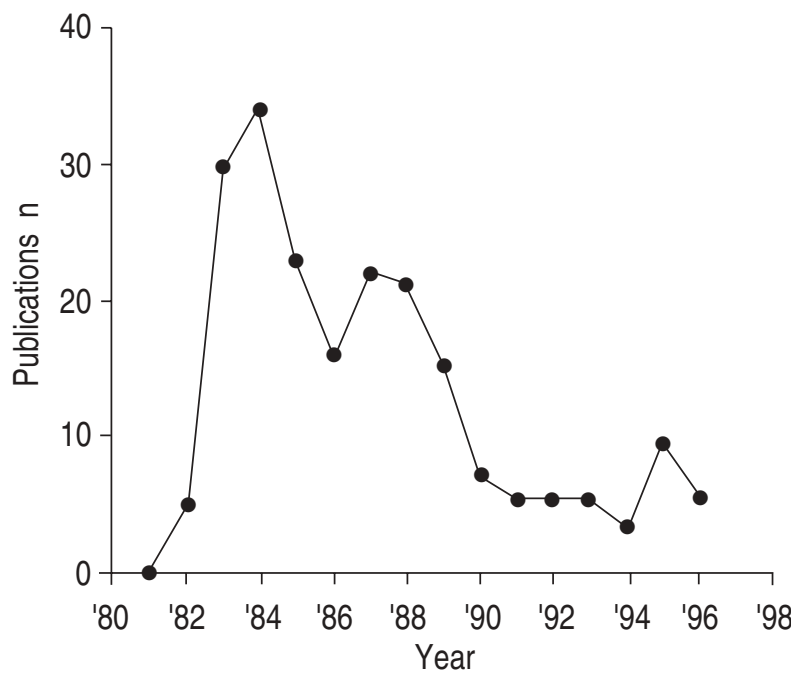

Fig. 2. - Number of clinical publications on amiodarone pneumonitis between the time of publication of the first case report (1980) and the time of writing (1996). Following an initial surge, the number of publications of adverse effect from many drugs tends to diminish with time. Thus, the information from cases that do not reach the stage of publication is epidemiologically lost. also associated with severe pneumonia [54]. Novel patterns of DIRD continued to be described, such as: multiple lung nodules following exposure to bleomycin [55]; cough during treatment with ACE inhibitors [56]; the haemolytic and uraemic syndrome with renal failure in patients exposed to mitomycin [57]; and pulmonary veno-occlusive disease following treatments with variegated chemotherapeutic agents [58]. A syndrome of fluid retention, pleural effusion and possibly ARDS was described in females during ovarian hyperstimulation $[59,60]$, and déjà-vu concerns arose from the resurgence of drug-induced pulmonary hypertension, following exposure to the then newer appetite depressant, fenfluramine [61].

The present decade has also brought substantial clinically relevant information to the area of DIRD. Drugs, such as fluoxetine [62], paclitaxel [63], ACE inhibitors [64], the cytokines interferon [65], granulocyte or granulocyte/monocyte colony-stimulating factor [66, 67], have been associated with interstitial pneumonia. Penicillamine-induced bronchiolitis obliterans remained almost restricted to the patient with rheumatoid arthritis, but tiopronin [68] and gold salts [69] have been shown to induce the syndrome as well. Newer clinical pictures emerged, such as the retinoic acid syndrome [70], and Ltryptophan-induced pulmonary eosinophilia, with occasional pulmonary hypertension, skin changes and fasciitis $[71,72]$, which almost reached the stage of an epidemic. Sadly, fenfluramine-induced pulmonary hypertension continues to be a problem, mainly in young females [73, 74], and this may lead to severe restriction of the use of this drug in the close future [75]. In addition to amiodarone, the causative role of which was amply confirmed [76], BOOP was related to radiation therapy [77] and to treatments with minocycline [78] or penicillamine [79]. It was also realized that disabling fibrosis could be detected years after the end of treatment with nitrosoureas [80].

In addition to laboratory work, which is clearly needed to further elucidate the fine mechanisms of druginduced lung disease [81], is there capacity for further clinical research into DIRD? Indeed, several avenues may be explored. Little is known about the epidemiology of DIRD. As shown in figure 2, once a drug leaves the forefront, and many do so sooner or later, the number of publications drops significantly, whilst the incidence of pneumonia to that drug remains little changed. Thus, most new cases of pneumonitis to the drug are "lost", epidemiologically speaking. We therefore need an improved method of collecting this information. Moreover, there are clinical settings in which we lack adequate information on DIRD. As examples, it is unclear whether cytokines potentiate the pneumotoxicity of chemotherapeutic agents, and this issue is debated [82]. It is also unclear whether mesalamine (5-aminosalicylic acid) should be stopped when pulmonary opacities develop in a patient with inflammatory bowel disease exposed to this drug [83]. Indeed, cases have been reported where pulmonary opacities have disappeared, even though the drug was maintained [84]; continuation of mesalamine may protect the patient from a flare-up of the bowel disease a few weeks later. Currently, we have no response to this question, and a prospective trial may be warranted before mesalamine is definitively blamed. We also lack 
sufficient data on methotrexate rechallenge, which has been performed harmlessly after methotrexate pneumonitis in a few patients with rheumatoid arthritis [85]. If a negative rechallenge could safely be predicted, then rheumatologists may reuse this excellent compound, and improve joint disability without the patient undergoing undue risk. We also lack epidemiological data on the prevalence of pleural changes in elderly persons exposed to ergolines, a curious and poorly-known syndrome that has recently been revisited [86].

Finally, we also need a warning system with a short time-constant, in order to rapidly detect potential questions raised by exposure to certain drugs, especially the newer ones. In this way, European pulmonologists may point more purposefully and with considerably more pertinent data than that available from isolated case reports, to almost any new drug-induced clinical problem. In addition to methotrexate and mesalamine, fluoxetine, recombinant cytokines and simvastin are now potential candidates for such an inquiry.

I believe that novel drug-induced lung diseases will relentlessly continue to emerge, as they have done in the past, and this is likely to fuel a strong level of interest in this area of pulmonology in the foreseeable future. We all need to be familiar with drug-induced respiratory disease in order to improve our own diagnostic accuracy and quality of care. Hopefully, the Groupe d'Etude de la Pathologie Iatrogène table and Web page will help us to advance in into that direction.

\section{References}

1. Foucher P, Biour M, Blayac JP, et al. Drugs which may injure the respiratory system. Eur Respir J 1997; 10: 265-279.

2. Dysart BR. Death following ingestion of five grains of acetylsalicylic acid. J Am Med Assoc 1933; 101: 446.

3. Ellis RV, McKinlay CA. Allergic pneumonia. $J$ Lab Clin Med 1941; 26: 1427-1432.

4. Falk MS, Newcomer VD. Loeffler's syndrome: occurrence in two patients treated with penicillin in oil and wax. J Am Med Assoc 1949; 141: 21-22.

5. Savilhati M. Pulmonary complication following use of gold salts. report of a case treated by BAL. Ann Med Int Fenn 1948; 37: 263-266.

6. Gernez-Rieux C, Breton A, Delwaulle P. A propos d'un cas d'oedème pulmonaire allergique aurique considérations générales sur l'oedème pulmonaire subaigu. J Franç Med Chir Thor 1950; 4: 213-224.

7. Garrell M. Löffler's syndrome: report of a case associated with the administration of aurothioglucose (Solganal). Arch Intern Med 1960; 106: 874-877.

8. Winterbauer RH, Wilske KR, Wheelis RF. Diffuse pulmonary injury associated with gold treatment. $N$ Engl J Med 1976; 294: 919-921.

9. Volk BW, Nathanson L, Losner S, Slade WR, Jacobi M. Incidence of lipoid pneumonia in a survey of 389 chronically ill patients. Am J Med 1951; 10: 316-324.

10. Jackson SLO. Acute perifocal reaction in tuberculosis due to PAS. Tubercle 1954; 35: 188-194.

11. Wold DE, Zahn DW. Allergic (Löffler's) pneumonitis occurring during antituberculous chemotherapy. Am Rev Tuberc 1956; 74: 445-453.

A French version of the GEPPI table in now available [87].
12. Rebhun J. Sensitivity to furadantin. US Armed Forces Med J 1956; 7: 1196-1200.

13. Reinhardt DJ, Waldron JM. Lupus erythematosus syndrome complicating hydralazine (Apresoline) therapy. $J$ Am Med Assoc 1954; 155: 1491-1492.

14. Sutcliffe J. Pulmonary oedema due to salicylates: with report of a case. Br J Radiol 1955; 28: 314-316.

15. Saltzstein SL, Ackerman LV. Lymphadenopathy induced by anticonvulsant drugs and mimicking clinically and pathologically malignant lymphomas. Cancer 1959; 12 : 164-182.

16. Doniach I, Morrison B, Steiner RE. Lung changes during hexamethonium therapy for hypertension. Br Heart $J$ 1954; 16: 101-108.

17. Gurtner HP. Pulmonary hypertension, "plexogenic pulmonary arteriopathy" and the appetite depressant drug aminorex: post or propter? Bull Eur Physiopathol Respir 1979; 15: 897-923.

18. Murray MJ, Kronenberg R. Pulmonary reactions simulating cardiac pulmonary oedema caused by nitrofurantoin. N Engl J Med 1965; 273: 1185-1187.

19. Sollaccio PA, Ribaudo CA, Grace WJ. Subacute pulmonary infiltration due to nitrofurantoin. Ann Intern Med 1966; 65: 1284-1286.

20. Morris AJ. Pulmonary and eosinophilic reaction to nitrofurantoin. Del Med J 1967; 39: 299-301.

21. Rosenow ECI, DeRemee RA, Dines DE. Chronic nitrofurantoin pulmonary reaction: report of five cases. $N$ Engl J Med 1968; 279: 1258-1262.

22. Walton CHA. Asthma associated with the use of nitrofurantoin. Can Med Assoc J 1966; 94: 40-41.

23. Khorsandian R, Bremer EM, Nodine JH. Anaphylactic reaction caused by treatment with nitrofurantoin. $J \mathrm{Am}$ Med Assoc 1963; 184: 500-502.

24. Israel HL, Diamond P. Recurrent pulmonary infiltration and pleural effusion due to nitrofurantoin sensitivity. $N$ Engl J Med 1962; 266: 1024-1026.

25. Oliner H, Schwartz R, Rubio Jr F, Dameshek W. Interstitial pulmonary fibrosis following busulfan therapy. Am J Med 1961; 31: 134-139.

26. Ishizuka $\mathrm{M}$, Takayama $\mathrm{H}$, Takeuchi $\mathrm{T}$, Umezawa $\mathrm{H}$. Activity and toxicity of bleomycin. $J$ Antibiot (Tokyo) 1967; 20: 15-24.

27. Acute Leukemia Group B. Acute lymphocytic leukemia in children. Maintenance therapy with methotrexate administered intermittently. J Am Med Assoc 1969; 207 : 923-928.

28. Wilson IC, Gambill JM, Sandifer MG. Loeffler's syndrome occurring during imipramine therapy. Am $J$ Psychiatr 1963; 119: 892-893.

29. Collins JR. Adverse reactions to salicylazosulfapyridine (Azulfidine) in the treatment of ulcerative colitis. South Med J 1968; 61: 354-358.

30. Graham JR, Suby HI, LeCompte PR, Sadowsky NL. Fibrotic disorders associated with methysergide therapy for headache. $N$ Engl J Med 1966; 274: 359-368.

31. Steinberg AD. Pulmonary edema following ingestion of hydrochlorothiazide. J Am Med Assoc 1968; 204: 167-168.

32. Holoye PY, Jenkins DE, Greenberg SD. Pulmonary toxicity in long-term administration of BCNU. Cancer Trent Rep 1976; 60: 1691-1694.

33. Hunt KK. Post-cyclophosphamide pneumonitis. $N$ Engl J Med 1972; 287: 668-669.

34. Andrews AT, Bowman HS, Patel SB, Anderson WM. Mitomycin and interstitial pneumonitis. Ann Intern Med 1979; 90: 127.

35. Weisenberger DD. Interstitial pneumonitis associated 
with azathioprine therapy. Am J Clin Pathol 1978; 69: 181-185.

36. Cole SR, Myers TJ, Kiatsky AU. Pulmonary disease with clorambucil therapy. Cancer 1978; 41: 455-459

37. Codling BW, Chakera TMH. Pulmonary fibrosis following therapy with melphalan for multiple myeloma. J Clin Pathol 1972; 25: 668-673.

38. Cameron DC. Diffuse pulmonary disorder caused by oxyphenbutazone. $\mathrm{Br}$ Med $J$ 1975; ii: 500-501.

39. Ho D, Tashkin DP, Bein ME, Sharma O. Pulmonary infiltrates with eosinophilia associated with tetracycline. Chest 1979; 76: 33-36.

40. Geddes DM, Corrin B, Brewerton DA, Davies RJ, TurnerWarwick M. Progressive airway obliteration in adults and its association with rheumatoid disease. $Q \mathrm{~J} \mathrm{Med}$ 1977; 46: 427-444.

41. Eastmond CJ. Diffuse alveolitis as complication of penicillamine treatment for rheumatoid arthritis. $\mathrm{Br} \mathrm{Med} J$ 1976; i: 1506.

42. Sternlieb I, Bennett B, Scheinberg IH. D-Penicillamine induced Goodpasture's syndrome in Wilson's disease. Ann Intern Med 1975; 82: 673-676.

43. Stubblefield PG. Pulmonary edema occurring after therapy with dexamethasone and terbutaline for premature labor. Am J Obstet Gynecol 1978; 132: 341-342.

44. Ward HN. Pulmonary infiltrates associated with leukoagglutinin transfusion reactions. Ann Intern Med 1970; 73: 689-694.

45. Anderson RJ, Potts DE, Gabow PA, Rumack BH, Schrier RW. Unrecognized adult salicylate intoxication. Ann Intern Med 1976; 85: 745-748.

46. De Vriese ASP, Philippe J, Van Renterghem DM, De Cuyper CA, Hindryckx EGJ, Louagie A. Carbamazepine hypersensitivity syndrome: report of 4 cases and review of the literature. Medicine (Baltimore) 1995; 74: 144 150.

47. Dyer NH, Varley CC. Practolol-induced pleurisy and constrictive pericarditis. Br Med J 1975; i: 443.

48. Rotmensch HH, Liron M, Tupilsky M, Laniado S. Possible association of pneumonitis with amiodarone therapy. Am Heart J 1980;100: 412-413.

49. Esinger W, Schleiffer T, Leinberger H, et al. Steroidrefraktäre Lungenfibrose durch Amiodaron. Dtsch Med Wschr 1988; 113: 1638-1641.

50. Camus P, Lombard JN, Perrichon M, et al. Bronchiolitis obliterans organising pneumonia in patients taking acebutolol or amiodarone. Thorax 1989; 44: 711-715.

51. Tuzcu EM, Maloney JD, Sangani BH, et al. Cardiopulmonary effects of chronic amiodarone therapy in the early postoperative course of cardiac surgery patients. Clev Clin J Med 1987; 54: 491-495.

52. Seigneur J, Tréchot P, Hubert J, Lamy P. Pulmonary complications of hormone treatment in prostate carcinoma. Chest 1988; 93: 1106.

53. Quesada JR, Libshitz HI, Hersh EM, Gutterman JU. Pulmonary abnormalities in patients intravenously receiving the methanol extraction residue (MER) of bacillus Calmette-Guérin. Cancer 1980; 45: 1340-1343.

54. Gispen JG, Alarcon GS, Johnson JJ, Acton RT, Barger BO, Koopman WJ. Toxicity to methotrexate in rheumatoid arthritis. J Rheumatol 1987; 14: 74-79.

55. Dineen MK, Englander LS, Huben RP. Bleomycininduced nodular pulmonary fibrosis masquerading as metastatic testicular cancer. J Urol 1986; 136: 473-475.

56. Berkin KE, Ball SG. Cough and angiotensin-converting enzyme inhibition. Br Med J 1988; i: 1279-1280.

57. Jolivet J, Giroux L, Laurin S, Gruber J, Bettez P, Band
PR. Microangiopathic anemia, renal failure, and noncardiogenic pulmonary edema: a chemotherapy-induced syndrome. Cancer Treat Rep 1983; 67: 429-434.

58. Joselson R, Warnock M. Pulmonary veno-occlusive disease after chemotherapy. Hum Pathol 1983;14: 8891.

59. Zosmer A, Katz Z, Lancet M, Konichezky S, SchwartzShoham Z. Adult respiratory distress syndrome complicating ovarian hyperstimulation syndrome. Fertil Steril 1987; 47: 524-526.

60. Kingsland CR, Collins JV, Rizk B, Mason BA. Ovarian hyperstimulation presenting as acute hydrothorax after in vitro fertilization. Am J Obstet Gynecol 1989; 161: 381-382.

61. Douglas JG, Munro JF, Kitchin AH, Muir AL, Proudfoot AT. Pulmonary hypertension and fenfluramine. $\mathrm{Br} \mathrm{Med}$ $J$ 1981; ii: 881-883.

62. Bass SP, Colebatch HJH. Fluoxetine-induced lung damage. Med J Aust 1992; 156: 364-365.

63. Goldberg HL, Vannice SB. Pneumonitis related to treatment with paclitaxel. J Clin Oncol 1995; 13: 534.

64. Obergassel L, Carlsson J, Tebbe U. ACE-hammer-assozierte interstitielle Lungeninfiltrate. Dtsch Med Wochenschr 1995; 120: 1273-1277.

65. Kamisako T, Adachi Y, Chihara J, Yamamoto T. Interstitial pneumonitis and interferon-alpha. BMJ 1993; i: 896.

66. Katoh M, Shikoshi K, Takada M, et al. Development of interstitial pneumonitis during treatment with granulocyte colony-stimulating factor. Ann Hematol 1993; 67: 201-202.

67. Seebach J, Speich R, Fehr J, Tuchschmid P, Russi E. GM-CSF-induced acute eosinophilic pneumonia. $\mathrm{Br} J$ Haematol 1995; 90: 963-965.

68. Demaziere A, Maugars Y, Chollet S, Prost A. Nonfatal bronchiolitis obliterans possibly associated with tiopronin: a case report with long-term follow-up. $\mathrm{Br} \mathrm{J}$ Rheumatol 1993; 32: 172-174.

69. Schwartzman KJ, Bowie DM, Yeadon C, Fraser R, Sutton ED, Levy RD. Constrictive bronchiolitis obliterans following gold therapy for psoriatic arthritis. Eur Respir $J$ 1995; 8: 2191-2193.

70. Frankel SR, Eardley A, Lauwers G, Weiss M, Warrell Jr RP. The "retinoic acid syndrome" in acute promyelocytic leukemia. Ann Intern Med 1992; 117: 292-296.

71. Bogaerts $\mathrm{Y}$, van Rentenghem D, Vanvuchelen $\mathrm{J}$, et al. Interstitial pneumonitis and pulmonary vasculitis in a patient taking an L-tryptophan preparation. Eur Respir J 1991; 4: 1033-1036.

72. Strumpf IJ, Drucker RD, Anders KH, Cohen S, Fajolu O. Acute eosinophilic pulmonary disease associated with ingestion of L-tryptophan-containing products. Chest 1991; 99: 8-13.

73. Pouwels HMM, Smeets JLRM, Cheriex EC, Wouters EFM. Pulmonary hypertension and fenfluramine. Eur Respir J 1990; 3: 606-607.

74. Abenhaim L, Moride Y, Brenot F, et al. Appetite-suppressant drugs and the risk of primary pulmonary hypertension. N Engl J Med 1996; 335: 609-616.

75. Voelkel NF. Drug-induced pulmonary hypertension: must history repeat itself? Pulm Pharmacol 1996; 9: 67-68.

76. Oren S, Turkot S, Golzman B, London D, ben-Dor D, Weiler Z. Amiodarone-induced bronchiolitis obliterans organizing pneumonia (BOOP). Respir Med 1996; 90: 167-169.

77. Bayle JY, Nesme P, Bejui-Thivolet F, Loire R, Guérin 
JC, Cordier JF. Migratory organizing pneumonitis "primed" by radiation therapy. Eur Respir J 1995; 8: 322-326.

78. Piperno D, Donné C, Loire R, Cordier JF. Bronchiolitis obliterans organizing pneumonia associated with minocycline therapy: a possible cause. Eur Respir J 1995; 8: 1018-1020.

79. Cohen AJ, King TE Jr, Downey GP. Rapidly progressive bronchiolitis obliterans with organizing pneumonia. Am J Respir Crit Care Med 1994; 149: 1670-1675.

80. O'Driscoll BR, Hasleton PS, Taylor PM, Poulter LW, Gattamaneni HR, Woodcock AA. Active lung fibrosis up to 17 years after chemotherapy with carmustine (BCNU) in childhood. N Engl J Med 1990; 323: 378382.

81. Camus P. Pathophysiology of drug-induced lung disease. In: White J, Akoun GM, eds. Treatment-induced Respiratory Disorders. Amsterdam, Elsevier, 1989: pp. 24-46.
82. Bastion Y, Coiffier B. Pulmonary toxicity of bleomycin: is G-CSF a risk factor? Lancet 1994; ii: 474.

83. Bitton A, Peppercorn MA, Hanrahan JP, Upton MP. Mesalamine-induced lung toxicity. Am J Gastroenterol 1996; 91: 1039-1040.

84. Camus P, Piard F, Ashcroft T, Gal AA, Colby TV. The lung in inflammatory bowel disease. Medicine (Baltimore) 1993; 72: 151-183.

85. Cook NJ, Carroll GJ. Successful reintroduction of methzotrexate after pneumonitis in two patients with rheumatoid arthritis. Ann Rheum Dis 1992; 51: 272-274.

86. Pfitzenmeyer P, Foucher P, Dermewald G, et al. Pleuropulmonary changes induced by ergoline drugs. Eur Respir J 1996; 9: 1013-1019.

87. Foucher P, Brour M, Godard P, Ollagnier M, Mayaud $\mathrm{C}$, Camus $\mathrm{P}$, and the GEPPI. Médicaments impliqés en pathologie pulmonaire iatrogène. Rev Mal Respir 1996; 13: 616-629. 